\title{
Total phenolic content of organic and conventional green leafy vegetables.
}

\author{
Jemima B Mohankumar*, L Uthira and Maheswari SU \\ Department of Nutrition and Dietetics, PSG College of Arts and Science, Coimbatore - 641014, TN, India
}

\begin{abstract}
Green Leafy Vegetables (GLVs) contain an immense variety of bioactive non-nutritive health enhancing factors. GLVs have an abundance of phenolic compounds. The AOA of phenolic compounds is mainly due to the redox properties, which allow them to act as reducing agents, hydrogen donors, singlet oxygen quenchers, heavy metal chelators and hydroxyl radical quenchers Total phenoplic content (TPC) of organic and conventional GLVs was determined using Folin-Ciocalteu reagent spectrophotometrically with Gallic acid as the standard. Fresh samples of GLVs were extracted separately with water, methanol and ethanol for the estimations. Curry leaves (Murraya koenigii), a commonly used green in most India preparations had the highest phenolic content ranging from $3468.80 \pm 88.03$ to $5084.53 \pm 123.49 \mu \mathrm{g}$ of GAE/g of FW in all the solvents of both OG and CV farming system. Agathi (Sesbania grandiflora) and fenugreek (Trigonella foenum graecum) had more polyphenolics in water extract. These greens are generally cooked in water medium; hence they are a valuable source of phenols in the diet. In our study, a one-way between extracts of solvents ANOVA was conducted to compare the effect of solvents used in the extraction of total phenols in each type of farming methods (OG or CV). The results elucidate that the quantity of total phenolics in GLVs varied among different extracting solvents.
\end{abstract}

Keywords: Green leafy vegetables, Organic, Conventional, Phenols, Folin-Ciocalteu.

Accepted on January $15^{\text {th }}, 2018$

\section{Introduction}

Phenols are aromatic compounds containing one or several hydroxyl groups directly attached to the benzene ring. According to the number of hydroxyl groups, phenols are classified as dihydric, trihydric and polyhydric. By the year 2005, thousands of polyphenolic compounds had been isolated from plants [1]. There are many spectrophotometric methods for the quantification of phenolic compounds in plant materials. Based on different principles, these methods are used to determine various structural groups present in the phenolic compounds. Spectrophotometric methods enable either the quantification of all extracted phenolics as a group [2-4] or the quantification of specific phenolic substances.

Green leafy vegetables (GLVs) are micronutrient dense nature's gift to mankind that provide more vitamins per mouthful than any other food. They are a rich source of calcium, iron, $\beta$-carotene, vitamin $\mathrm{C}$, dietary fibre and many trace minerals. GLV also contain an immense variety of bioactive non-nutritive health enhancing factors such as antioxidants, phytochemicals, essential fatty acids and dietary fibre. There has been a growing recognition of importance of these phyto nutrients in the prevention of non-communicable disease especially in the past two decades. Various studies reported the presence of abundant phenolic compounds some of them namely quercitin, kaempferol and acacetin in GLVs [5]. The commonly consumed greens are coriander (Coriandrum sativum), curry leaves (Murraya koenigii), amaranth, mint (Mentha spicata), fenugreek (Trigonella foenum graecum), drumstick (Moringa oleifera) etc. These greens are inexpensive, and it is advisable to include at $50 \mathrm{~g}$ in one's diet daily. They contain vital nutrient required for growth and maintenance of health.
Polyphenols encompass several classes of weakly acidic chemicals related to, or built upon the phenyl ring. Polyphenols contain one or more phenolic hydroxyl groups directly attached to these carbon-based aromatic phenyl-ring compounds. Reactive Oxygen Species (ROS) easily oxidize these to quinones, a property that helps account for their free radical scavenging capacity. Polyphenols have diverse functions in plants and are a major class of secondary plant metabolites. The major plant Polyphenols by volume is lignin [6]. Plant polyphenols may have beneficial and/or detrimental effects on mammals. After plants die, phenolic compounds can persist for weeks and affect decomposition. They also have an impact on the shelf life of harvested produce [7].

In the present study, Total Phenolic Content (TPC) of the selected samples was estimated by using Folin-Ciocalteu method. The data obtained was consolidated and tabulated for statistical analyses. We hypothesised that there is no difference between the total phenolic content of $\mathrm{OG}$ and conventionally grown GLV. In addition, we used three solvents for the extraction of phenols, viz., water, methanol and ethanol and hypothesised that there is no difference in the quantities of phenols in the extracts using the three solvents.

\section{Materials and Methods}

\section{Description of Folin-Ciocalteu reagent}

The Folin-Ciocalteu (F-C) method of assay is the simplest method available for the measurement of phenolic content in products. This method is a development of Folin-Denis reagent used in the early 19th century for the determination of tyrosine in proteins [8]. F-C reagent can be prepared by dissolving 100 g sodium tungstate (VI) dihydrate and $25 \mathrm{~g}$ sodium molybdate 
(VI) dihydrate with $700 \mathrm{ml}$ distilled water, $100 \mathrm{ml}$ concentrated hydrochloric acid, and $50 \mathrm{ml}$ of $85 \%$ phosphoric acid to which is added $150 \mathrm{~g}$ of lithium sulphate hydrate. This reagent is very stable if protected from reductant and light even if diluted. For many years now, the F-C method of assay has been in use as a measure of Polyphenols in natural products, and the basic mechanism is an oxidation/ reduction reaction with the phenolic group being oxidized and the metal ion reduced [9].

\section{Procurement of chemicals}

Folin-Ciocalteu's reagent for phenols, sodium carbonate monohydrate (reagent grade) and HPLC grade Methanol were purchased from Hi-Media Laboratories Pvt. Ltd, Mumbai, India. Gallic acid from Sigma Chemicals, St. Louis, MO, USA, Absolute Ethanol, and Demineralised Water were of analytical grade and supplied by the local agent.

\section{Protocol}

The quantity of TPC was determined using Folin-Ciocalteau reagent as per the method proposed by [2] and Gallic acid was used as the standard. The absorption was measured at $725 \mathrm{~nm}$ using UV VIS double beam spectrophotometer. The method was validated according to national and international guidelines. The optimum conditions for analysis time, wavelength, and standard substance were $30 \mathrm{~min}, 760 \mathrm{~nm}$, and Gallic acid, respectively. Under these conditions, validation by $\mathrm{UV} / \mathrm{Vis}$ spectrophotometry proved the method linear, specific, precise, accurate, reproducible, robust, and easy to perform. The requirements for analytical application and the reliability of the results were met by this method.

\section{Standardization}

The standard curve was obtained using gallic acid for total phenolic content. The calibration curve was plotted between the concentrations of 0-50 $\mu \mathrm{g}$ of Gallic acid (Figure 1) for phenolics.

The results of total phenolic content were expressed in $\mu \mathrm{g}$ of Gallic acid equivalence (GAE) /g Fresh Weight (FW). The increase in absorbance is based on the intensity of colour developed and is directly proportional to concentration of standard for total phenolics. The $\mathrm{R}^{2}$ value obtained in the calibration curve was 0.9946 , for total phenolics, All the assays were carried out in UV-Vis Double Beam Spectrophotometer of Systronics, Model No. 2201. All the procedures were done in triplicates and for concordant values.

\section{Preparation of extracts}

The extract was prepared according to the method used earlier by others with some modifications [10]. One hundred gram of the plant material was weighed, macerated and homogenized. Five to ten grams of the homogenised sample was extracted with distilled water, methanol or $80 \%$ ethanol. Extraction was carried out for $2 \mathrm{~h}$ at $50^{\circ} \mathrm{C}$ using an orbital shaker at 200 $\mathrm{rpm}$. The ratio of samples to extraction medium was $1: 25$. The mixture was centrifuged at $2500 \mathrm{rpm}$ and the supernatant was transferred into brown bottles and stored at $-4^{\circ} \mathrm{C}$. The extracts were suitable diluted for the estimation of total phenols. The extraction solvent selected was $80 \%$ ethanol based on the results [11] using some common Malaysian herbs while water is the usual solvent used by the public when consuming these GLVs [12].

\section{Determination of total phenolic content}

TPC of the samples were evaluated using Folin-Ciocalteu reagent [13], in which $150 \mu$ l of samples were diluted with 2400 $\mu 1$ of deionized water. Thereafter, $150 \mu \mathrm{l}$ of Folin-Ciocalteu reagent $(0.25 \mathrm{~N})$ was added, mixed for 3 minutes and the reaction mixture was then neutralized with $300 \mu \mathrm{l}$ of $\mathrm{Na}_{2} \mathrm{CO}_{3}$ (1N). The final mixture was incubated for $2 \mathrm{~h}$ in the dark and UV absorbance were taken at $725 \mathrm{~nm}$. Gallic acid was used as standard and results were reported in micromol gallic acid equivalent per gram fresh weight ( $\mu \mathrm{M} \mathrm{GAE} / \mathrm{g}$ FW).

\section{Results and Discussion}

Antioxidant potential of phenolic compounds is a scientifically established reality now [14]. The data on TPC of GLVs are given in Tables 1 and 2 for organic and conventional samples separately. Ten GLVs were analyzed for TPC using water, methanol and ethanol solvents according to the procedure explained in the above section.

Curry leaves (Murraya koenigii) had the highest phenolic content ranging from $3468.80 \pm 88.03$ to $5084.53 \pm 123.49$ $\mu \mathrm{g}$ of GAE/g of FW in all the solvents of both $\mathrm{OG}$ and $\mathrm{CV}$ farming system. The TPC of GLVs are in the following order: curry leaves (Murraya koenigii)> mint (Mentha spicata)> agathi (Sesbania grandiflora) $>$ fenugreek (Trigonella foenum graecum) $>$ manathakkali (Solanum nigrum) $>$ coriander (Coriandrum sativum). The table below gives the data obtained in the present study.

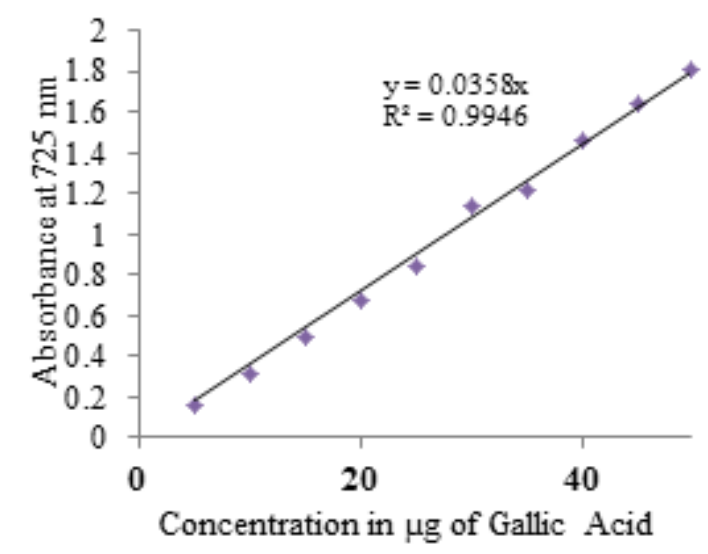

Figure 1. Standard curve of gallic acid - Total phenol content assay. 
Table 1. Total phenolic content of organic green leafy vegetables.

\begin{tabular}{|c|c|c|c|c|c|}
\hline \multirow{2}{*}{ S. no } & \multirow{2}{*}{ Name of the Green Leafy Vegetable } & \multicolumn{4}{|c|}{ ( $\mu \mathrm{g}$ of $\mathrm{GAE} / \mathrm{g}$ of $\mathrm{FW}$ ) } \\
\hline & & Ethanol & Methanol & Water & Total \\
\hline \multirow{2}{*}{1} & \multirow{2}{*}{$\begin{array}{c}\text { Agathi } \\
\text { (Sesbania grandiflora) }\end{array}$} & 1455.9 & 1473.95 & 1661.65 & \multirow{2}{*}{$4591.50^{b}$} \\
\hline & & \pm 49.33 & \pm 37.02 & \pm 36.56 & \\
\hline 2 & $\begin{array}{c}\text { Araikeerai } \\
\text { (Amaranthus tristis) }\end{array}$ & \multicolumn{4}{|c|}{ Samples not available } \\
\hline \multirow{2}{*}{3} & \multirow{2}{*}{$\begin{array}{c}\text { Coriander } \\
\text { (Coriandrum sativum) }\end{array}$} & 404.28 & 477.62 & 349.16 & \multirow{2}{*}{$1231.06^{f}$} \\
\hline & & \pm 20.47 & \pm 39.25 & \pm 30.51 & \\
\hline \multirow{2}{*}{4} & \multirow{2}{*}{$\begin{array}{c}\text { Curry } \\
\text { (Murraya koenigii) }\end{array}$} & 4926.76 & 5084.53 & 4357.54 & \multirow{2}{*}{$14368.83^{a}$} \\
\hline & & \pm 259.54 & \pm 123.49 & \pm 155.52 & \\
\hline \multirow{2}{*}{5} & \multirow{2}{*}{$\begin{array}{c}\text { Moringa } \\
\text { (Moringa oleifera) }\end{array}$} & 3414.63 & 3222.07 & 2606.72 & \multirow{2}{*}{9243.42} \\
\hline & & \pm 113.26 & \pm 66.43 & \pm 48.54 & \\
\hline \multirow{2}{*}{6} & \multirow{2}{*}{$\begin{array}{c}\text { Fenugreek } \\
\text { (Trigonella foenum Graecum) }\end{array}$} & 1210.43 & 1420.38 & 1599.63 & \multirow{2}{*}{$4230.44^{d}$} \\
\hline & & \pm 33.47 & \pm 28.11 & \pm 58.68 & \\
\hline \multirow{2}{*}{7} & \multirow{2}{*}{$\begin{array}{c}\text { Pulicha } \\
\text { (Hibiscus canabinus) }\end{array}$} & 3544.34 & 3769.17 & 177.23 & \multirow{2}{*}{7490.74} \\
\hline & & \pm 166.57 & \pm 228.95 & \pm 5.47 & \\
\hline \multirow{2}{*}{8} & \multirow{2}{*}{$\begin{array}{c}\text { Manathakkali } \\
\text { (Solanum nigrum) }\end{array}$} & 931.95 & 1235.26 & 1051.96 & \multirow{2}{*}{$3219.17^{e}$} \\
\hline & & \pm 27.47 & \pm 37.37 & \pm 10.17 & \\
\hline \multirow{2}{*}{9} & \multirow{2}{*}{$\begin{array}{c}\text { Mint } \\
\text { (Mentha spicata) }\end{array}$} & 1123.32 & 2294.72 & \multirow{2}{*}{$1151.08 \pm 47.96$} & \multirow{2}{*}{$4569.12^{c}$} \\
\hline & & \pm 79.27 & \pm 112.01 & & \\
\hline \multirow{2}{*}{10} & \multirow{2}{*}{$\begin{array}{c}\text { Ponnaganni } \\
\text { (Alternathera sessilis) }\end{array}$} & 1214.56 & 1190.96 & 875.57 & \multirow{2}{*}{3210.09} \\
\hline & & \pm 33.63 & \pm 49.10 & \pm 10.31 & \\
\hline
\end{tabular}

Table 2. Total phenolic content of conventional green leafy vegetables.

\begin{tabular}{|c|c|c|c|c|c|}
\hline \multirow{2}{*}{ S. no } & \multirow{2}{*}{ Name of the Green Leafy Vegetable } & \multicolumn{4}{|c|}{ ( $\mu \mathrm{g}$ of $\mathrm{GAE} / \mathrm{g}$ of $\mathrm{FW})$} \\
\hline & & Ethanol & Methanol & Water & Total \\
\hline \multirow{2}{*}{1} & \multirow{2}{*}{$\begin{array}{c}\text { Agathi } \\
\text { (Sesbania grandiflora) }\end{array}$} & 1310.57 & 1247.32 & 1382.59 & \multirow{2}{*}{$3940.48^{c}$} \\
\hline & & \pm 55.36 & \pm 44.82 & \pm 34.29 & \\
\hline \multirow{2}{*}{2} & \multirow{2}{*}{$\begin{array}{c}\text { Araikeerai } \\
\text { (Amaranthus tristis) }\end{array}$} & 376.83 & 379.99 & 451.98 & \multirow{2}{*}{1208.8} \\
\hline & & \pm 28.99 & \pm 10.97 & \pm 18.23 & \\
\hline \multirow{2}{*}{3} & \multirow{2}{*}{$\begin{array}{c}\text { Coriander } \\
\text { (Coriandrum sativum) }\end{array}$} & 767.93 & 894.74 & 626.88 & \multirow{2}{*}{$229.55^{f}$} \\
\hline & & \pm 37.55 & \pm 28.45 & \pm 8.89 & \\
\hline \multirow{2}{*}{4} & \multirow{2}{*}{$\begin{array}{c}\text { Curry } \\
\text { (Murraya koenigii) }\end{array}$} & 3468.8 & 4171.32 & 4404.1 & \multirow{2}{*}{$12044.22^{\mathrm{a}}$} \\
\hline & & \pm 88.03 & \pm 112.89 & \pm 506.91 & \\
\hline 5 & $\begin{array}{c}\text { Moringa } \\
\text { (Moringa oleifera) }\end{array}$ & \multicolumn{4}{|c|}{ Samples not available } \\
\hline \multirow{2}{*}{6} & \multirow{2}{*}{$\begin{array}{c}\text { Fenugreek } \\
\text { (Trigonella foenum Graecum) }\end{array}$} & 562.24 & 576.23 & 744.8 & \multirow{2}{*}{$1883.27^{d}$} \\
\hline & & \pm 13.52 & \pm 34.29 & \pm 37.30 & \\
\hline 7 & $\begin{array}{c}\text { Pulicha } \\
\text { (Hibiscus canabinus) }\end{array}$ & \multicolumn{4}{|c|}{ Samples not available } \\
\hline \multirow{2}{*}{8} & \multirow{2}{*}{$\begin{array}{c}\text { Manathakkali } \\
\text { (Solanum nigrum) }\end{array}$} & 886.86 & 1160.65 & 983.53 & \multirow{2}{*}{$3031.04^{\mathrm{e}}$} \\
\hline & & \pm 27.52 & \pm 27.70 & \pm 40.56 & \\
\hline \multirow{2}{*}{9} & \multirow{2}{*}{$\begin{array}{c}\text { Mint } \\
\text { (Mentha spicata) }\end{array}$} & 1116.09 & 2046.25 & 1096.92 & \multirow{2}{*}{$4258.26^{b}$} \\
\hline & & \pm 31.04 & \pm 86.74 & \pm 138.72 & \\
\hline 10 & $\begin{array}{c}\text { Ponnaganni } \\
\text { (Alternathera sessilis) }\end{array}$ & \multicolumn{4}{|c|}{ Samples not available } \\
\hline
\end{tabular}

The other GLVs were found to have varying levels of phenols. The quantity of phenolics ranging from $177.23 \pm 5.47$ to 5084.53 \pm 123.49 expressed as $\mu \mathrm{g}$ of GAE/g FW of GLVs. In the OG and CV GLVs methanolic extracts had the highest TPC in mint (Mentha spicata), coriander (Coriandrum sativum) leaves, manathakkali leaves (Solanum nigrum). Curry leaves (Murraya koenigii) had higher phenolic content in OG methanolic extracts whereas agathi (Sesbania grandiflora) and fenugreek (Trigonella foenum graecum) had more polyphenolics in water extract. The amount of total phenolics in water extracts ranged from $349.16 \pm 30.51$ to $4404.10 \pm 506.91 \mu \mathrm{g}$ of GAE/g FW.

TPC in curry leaves (Murraya koenigii) and fenugreek leaves (Trigonella foenum graecum) had similar amount of Polyphenols [15] which was $158.33 \mathrm{mg}$ of tannic acid/ $100 \mathrm{~g}$. However, some others [16] reported that total phenols in fenugreek leaves (Trigonella foenum graecum) was $217.5 \mathrm{mg}$ of catechol/ $100 \mathrm{~g} \mathrm{FW}$.
Reported TPC of some common GLVs ranged from 5.0 to 69.5 $\mathrm{mg}$ of TAE/ $\mathrm{g}$ of extracts [17]. Therefore, it can be said that the TPC of vegetables varies widely depending on the variety of vegetables. Comparison is difficult, as method of extraction solvents used; method adopted to extract phenol and standard compounds adopted varied among the studies.

Curry leaves (Murraya koenigii) had the highest extraction yield $(1.65 \%)$ and TPC was $38.6 \%$ among the tested samples of curry leaves (Murraya koenigii) [18]. TPC of curry leaves (Murraya koenigii) in three different climates (India, Nicaragua and Niger) ranged from 2940-4250 $\mathrm{mg}$ of GA/ g of DW [19]; in water extracts, it was $257-3234 \mathrm{mg}$ TAE/ $100 \mathrm{~g}$ of DW [20]. TPC in absolute methanolic and $70 \%$ ethanolic extract was $26.46 \pm 0.20$ and $12.31 \pm 0.18 \mathrm{mg} \mathrm{GAE} / \mathrm{g}$ DW respectively [21].

Coriander leaves (Coriandrum sativum), curry leaves (Murraya koenigii), manathakkali leaves (Solanum nigrum) and mint 
(Mentha spicata) had greater phenol content in methanolic extracts than ethanol and water. Furthermore, methanol is the most suitable solvent in the extraction of polyphenol compounds due to its ability to inhibit the reaction of polyphenol oxidase that causes the oxdation of phenolics and its ease of evaporation compared to water [22].

However, highest phenolic content was also observed in ethanolic extracts of OG ponnaganni (Alternathera sessilis) and moringa (Moringa oleifera) leaves and water extracts of OG and CV agathi (Sesbania grandiflora), fenugreek leaves (Trigonella foenum graecum) and CV araikeerai (Amaranthus tristis) (Figure 2).

GLVs namely Araikeerai (Amaranthus tristis), Moringa (Moringa oleifera), Pulicha keerai (Hibiscus canabinus) and Ponnaganni (Alternathera sessilis) for those either equivalent OG or CV counterparts were not available. The graph was plotted using mean values of three extracts of both farming methods

Among the GLVs assayed, which did not have an OG or CV counterpart, OG moringa greens (Moringa oleifera) had the highest TPC followed by pulicha greens (Hibiscus canabinus), ponnaganni (Alternathera sessilis) and arai keerai. The TPC in OG pulicha (Hibiscus canabinus) and moringa greens (Moringa oleifera) ranged from $177.23 \pm 5.47$ to $3769.17 \pm$ 228.95 and $2606.72 \pm 48.54$ to $3414.63 \pm 113.26 \mu \mathrm{g}$ of GAE/g FW respectively. Apart from this, water extracts had lower phenol content in all the unpaired GLVs except CV araikeerai (Amaranthus tristis) which had $451.98 \pm 38.23 \mu \mathrm{g}$ of GAE/g FW. The results elucidate that the quantity of total phenolics in GLVs varied among different extracting solvents.

Reported TPC was highest in methanolic extracts of radish leaves $(86.16 \pm 4.5 \mathrm{mg} / \mathrm{g} \mathrm{DW})$, medium in ethyl acetate and water extracts $(36.81 \pm 1.70$ and $34.16 \pm 3.44 \mathrm{mg}$ of catechin $/ \mathrm{g}$ DW respectively [23]). The extraction yield of curry leaves (Murraya koenigii) was higher in ethanol and water extracts and least in hexane extract. The TPC was 140 and $255 \mathrm{mg}$ of GAE/ g DW in ethanol extracts at ambient temperature [24].

TPC in leaves of amaranth species and spinach leaves was 84.9 \pm 13.02 and $33.8 \pm 7.33 \mathrm{mg}$ of GA/ $100 \mathrm{~g}$ respectively in the raw food sample [25]. The phenol content was higher in amaranth species and it was directly proportional to the AOA measured using $\beta$-carotene and linoleic acid system. In their study, they also added that the phenol content was ranked first in GLVs assayed when compared to other vegetables and roots and tubers.

In our study, a one-way between extracts of solvents ANOVA was carried to compare the effect of solvents used in the extraction of total phenols in each type of farming methods (OG or CV). There was a significant effect on TPC by the extraction medium at the $\mathrm{p} \leq 0.05$ level for mint (Mentha spicata) $\{\mathrm{OG}$ $[\mathrm{F}(2,6)=190.3, \mathrm{p}=0.00]\}$ and $\{\mathrm{CV}-[\mathrm{F}(2,6)=95.7, \mathrm{p}=0.00]\}$; curry leaves (Murraya koenigii) $\{\mathrm{OG}-[\mathrm{F}(2,6)=12.3, \mathrm{p}=0.00]\}$ and $\{\mathrm{CV}-[\mathrm{F}(2,6)=190.3, \mathrm{p}=0.00]\}$; manathakkali leaves (Solanum nigrum) $\{\mathrm{OG}-[\mathrm{F}(2,6)=93.1, \mathrm{p}=0.00]\}$ and $\{\mathrm{CV}$ - $[\mathrm{F}(2,6)=54.8, \mathrm{p}=0.00]\}$; agathi (Sesbania grandiflora) greens $\{\mathrm{OG}-[\mathrm{F}(2,6)=22.7, \mathrm{p}=0.00]\}$ and $\{\mathrm{CV}-[\mathrm{F}(2,6)=6.6$, $\mathrm{p}=0.03]\}$; fenugreek leaves (Trigonella foenum graecum) $\{\mathrm{OG}$ $[\mathrm{F}(2,6)=63.8, \mathrm{p}=0.00]\}$ and $\{\mathrm{CV}-[\mathrm{F}(2,6)=33.8, \mathrm{p}=0.00]\}$; pulicha greens (Hibiscus canabinus) $\{\mathrm{OG}-[\mathrm{F}(2,6)=454.3$, $\mathrm{p}=0.00]\}$; ponnaganni (Alternathera sessilis) $\{\mathrm{OG}-[\mathrm{F}(2,6)=$ 88.4, $\mathrm{p}=0.00]\}$; aria keerai $\{\mathrm{CV}-[\mathrm{F}(2,6)=12.5, \mathrm{p}=0.00]\}$; and moringa greens (Moringa oleifera) $\{\mathrm{OG}-[\mathrm{F}(2,6)=81.8$, $\mathrm{p}=0.00]\}$.

The most probable reasons for these variations in the values may be due to reason that phenolic compounds may be water-soluble, lipid soluble, insoluble, or bound to cell walls. Therefore, the efficiency in extraction is a very important factor in quantitative analysis of AOA of food samples besides the natural occurring causes of the variation

Different levels reported in these studies may be attributed to the different plant species, crops, protocol of analyses and standards used to express TPC by the investigators. The AOA of phenolic compounds is mainly due to the redox properties, which allow them to act as reducing agents, hydrogen donors, singlet oxygen quenchers, heavy metal chelators and hydroxyl radical quenchers [15]. The antioxidant activity of phenolic compounds is mainly due to its redox properties, which can play an important role in adsorbing and neutralizing free radicals, quenching singlet and triplet oxygen, or decomposing peroxides [26].

\section{Conclusion}

The results of this study indicate that GLVs had phenolics that vary widely in different extracts and agricultural pattern. Further

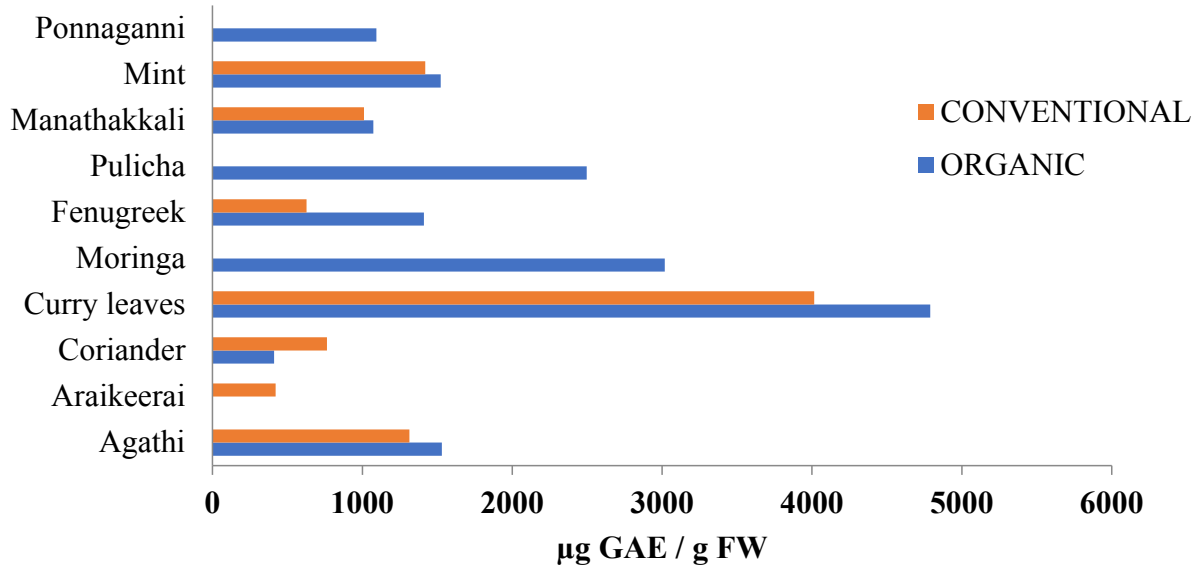

Figure 2. Total phenolic content of green leafy vegetables. 
research is needed to find out the various factors influencing phenolic content in plants.

Hence, from our analyses of total phenolics we reject the null hypothesis and conclude that the TPC of OG and CV GLVs are different. With respect to the extraction solvents used, phenol is extracted in different amounts in ethanol, methanol and water solvents, therefore we reject the null hypothesis and conclude that phenolic content varied among solvents and farming methods.

\section{Acknowledgements}

The authors are grateful for the funding received from the University Grants Commission, New Delhi, India, under the Major Research Project for College/University Teachers to carry out the research work.

\section{References}

1. Prior RL. Antioxidant capacity of tea and common vegetables. J Agric Food Chem. 1995;44:3426-3431.

2. Swain T, Hillis WE. Phenolic constituents of Prunus domestica I - Quantitative analysis of phenolic constituents. J Sci Food Agric. 1959;10: 63-68.

3. Price ML, Scoyoc VS, Butler LG. A critical evaluation of the vanillin reaction as an assay for tannin in sorghum. $\mathrm{J}$ Agric Food Chem. 1978;26:1214-1218

4. Earp CF, Akingbala JO, Ring SH, et al. Evaluation of several methods to determine tannins in sorghum with varying kernel characteristics. Cereal Chem. 1981;58: 234- 238.

5. Nambiar VS, Daniel M, Guin P. Characterization of polyphenols from coriander leaves (Coriandrum sativum). Red Amaranthus (A. paniculatus) and Green Amaranthus (A. frumentaceus) using paper chromatography: and their health implications. J. Herbal Medicine and Toxicology. 2010;4:173-177.

6. Daniel O, Meier MS, Schlatter J, et al. Selected phenolic compounds in cultivated plants: ecologic functions, health implication, and modulation by pesticides. Environ Health Perspect. 1999;107: 109-114.

7. Benbrook CM (2005) Elevating antioxidant levels in food through organic farming and food processing, The Organic Center, Foster, R.I. 2005; p. 81.

8. Folin O, Ciocalcuteu V. Tyrosine and tryptophan determinations in proteins. J Biol Chem. 1927;73:627-650.

9. Singleton VL, Orthofer R, Lamuela-Raventos RM (1999) Analysis of total phenols and other oxidation substances by means of Folin-Ciocalteu reagent. Methods Enzymol. 1999;299:152-178.

10. Velioglu YS, Mazza G, Gao L, et al. Antioxidant activity and total phenolics in selected fruits, vegetables and grain products. J Agric Food Chem. 1998;46:4113-4117.
11. Yoo KM, Lee $\mathrm{CH}$, Lee $\mathrm{H}$, et al. Relative antioxidant and cytoprotective activities of common herbs. Food Chemistry 2008;106:929- 936.

12. Wong SP, Leong LP, Koh WJH Antioxidant activities of aqueous extracts of selected plants. Food Chemistry 2006;99:775-783.

13. Thaipong K, Boonprakob U, Crosby K, et al. Comparison of ABTS, DPPH, FRAP, and ORAC assays for estimating antioxidant activity from guava fruit extracts, J. Food Compos Anal. 2006;19: 669-675.

14. Bhuyan LP, Sabhapondit S, Baruah BD, et al. Polyphenolic compounds and antioxidant activity of CTC black tea of North-East India. Food Chemistry. 2013;141: 3744-3751.

15. Gupta S, Prakash J. Influence of antioxidant components on antioxidant activity of dehydrated green leafy vegetables. Food Science and Technological Research. 2008;14:104-109.

16. Kaur C, Kapoor HC. Antioxidant activity and total phenolic content of some Asian vegetables, International J Food Sci Technol. 2002;37:153-161.

17. Shyamala BN, Gupta S, Lakshmi JA, et al. Leafy vegetable extracts-antioxidant activity and effect on storage stability of heated oils. Innov Food Sci Emerg Technol. 2005;6:239-245.

18. Huda FN, Noriham A, Norrakiah AS, et al. Antioxidant activity of plant methanolic extracts containing phenolic compounds. Afr J Biotechnol. 2009;8:484-489.

19. Siddhuraju P, Becker K. Antioxidant properties of various solvent extracts of total phenolic constituents from three different agroclimatic origins of drumstick tree (Moringa oleifera L.) leaves. J Agric Food Chem. 2003;51: 2144-2155.

20. Noriham A, Babji AS, Aminah A. Determination of antioxidative activities of selected Malaysian plant extracts. ASEAN Food Journal. 2004;13:193-199.

21. Almey AAA, Ahmed JKC, Zahir SI, et al. Total phenolic content and primary antioxidant activity of methanolic and ethanolic extracts of aromatic plants' leaves. Int Food Res J. 2010;17:1077-1084

22. Yao Y, W Sang, M Zhou, et al. Phenolic composition and antioxidant activities of 11 celery cultivars, J Food Sci. 2010;75:C9-C13.

23. Saxena K, Venkaiah P, Anitha P, et al. Antioxidant activity of commonly consumed plant foods in India: contribution of their phenolic content. Int J Food Sci Nutr. 2007;58:250-260.

24. Beevi SS, Narasu ML, Gowda BB Polyphenolics profile, antioxidant and radical scavenging activity of leaves and stem of Raphanus sativus L. Plant Foods Hum Nutr. 2010;65:8-17.

25. Menon AN, Sasidharan I. A study of antioxidant properties of different extracts of curry leaf (Murraya koenigii L.), Electronic Journal of Environmental, Agricultural and Food Chemistry. 2010;9:1036-1046. 
Citation: Mohankumar JB, Uthira L, Maheswari SU. Total phenolic content of organic and conventional green leafy vegetables. J Nutr Hum Health. 2018;2(1):1-6

26. Osawa T, Novel P. Natural antioxidants for utilization in food and biological systems. Scientific Societies Press, Tokyo, Japan. 1994;241-251.

\section{*Correspondence to:}

Dr. Jemima Beryl Mohankumar,

Emeritus Professor,

Department of Nutrition and Dietetics,

PSG College of Arts and Science,

Coimbatore,

Tamil Nadu,

India.

Tel: 9443754589

E-mail:mohanjemi1502@yahoo.com 